\title{
Welcome to the Journal of Environmental Exposure Assessment
}

\author{
Stuart Harrad', Daniel C. W. Tsang ${ }^{2}$, Suwanna Kitpati Boontanon ${ }^{3,4}$, Xiao-Jun Luo $^{5}$, Ovokeroye A. Abafe ${ }^{6}$, \\ Habib Bagheri ${ }^{7}$, Ethel Eljarrat ${ }^{8}$, Thanh Wang ${ }^{9}$, Bice Martincigh ${ }^{10}$, Habibullah Al-Mamun ${ }^{11}$, Hong-Jun Mao ${ }^{12}$, \\ Adeel Mahmood ${ }^{13}$, Giulia Poma ${ }^{14}$, Cassandra Rauert ${ }^{15}$, Lisa Melymuk ${ }^{16,17}$ \\ ${ }^{1}$ School of Geography, Earth and Environmental Sciences, University of Birmingham, Birmingham B9 4NH, United Kingdom. \\ ${ }^{2}$ Department of Civil and Environmental Engineering, The Hong Kong Polytechnic University, Hung Hom, Kowloon, Hong Kong \\ 999077, China. \\ ${ }^{3}$ Civil and Environmental Engineering Department, Faculty of Engineering, Mahidol University, Nakhon Pathom 73170, Thailand. \\ ${ }^{4}$ Graduate School of Global Environmental Studies, Kyoto University, Kyoto 606-8501, Japan. \\ ${ }^{5}$ State Key Laboratory of Organic Geochemistry and Guangdong Key Laboratory of Environmental Resources Utilization and \\ Protection, Guangzhou Institute of Geochemistry, Chinese Academy of Sciences, Guangzhou 510640, China. \\ ${ }^{6}$ Chemical Residue Analysis Laboratory, Agricultural Research Council-OVR, Pretoria 0110, South Africa. \\ ${ }^{7}$ Department of Chemistry, Sharif University of Technology, Tehran 11365-9516, Iran. \\ ${ }^{8}$ Environmental Chemistry Department, Institute of Environmental Assessment and Water Research (IDAEA-CSIC), Barcelona \\ 08034, Spain. \\ ${ }^{9}$ Man-Technology-Environment (MTM) Research Centre, Örebro University, Örebro SE-701 82, Sweden. \\ ${ }^{10} \mathrm{School}$ of Chemistry and Physics, University of KwaZulu-Natal, Westville Campus, Private Bag X54001, Durban 4000, South \\ Africa. \\ "Department of Fisheries, University of Dhaka, Dhaka 1000, Bangladesh. \\ ${ }^{12}$ Center of Urban Transport Emission Research, Department of Environmental Science and Engineering, Nankai University, \\ Tianjin 300300, China. \\ ${ }^{13}$ Department of Environmental Sciences, GC Women University Sialkot, Sialkot 51310, Pakistan. \\ ${ }^{14}$ Toxicological Centre, University of Antwerp, Universiteitsplein 1, Wilrijk 2610, Belgium. \\ ${ }^{15}$ Queensland Alliance for Environmental Health Sciences (QAEHS), The University of Queensland, Queensland 4000, Australia. \\ ${ }^{16}$ RECETOX, Masaryk University, Brno 61500, Czechia. \\ ${ }^{17}$ Department of Earth Sciences, University of Toronto, Toronto, M5S 3B1, Canada.
}

Correspondence to: Prof. Stuart Harrad, School of Geography, Earth and Environmental Sciences, University of Birmingham, Edgbaston, Birmingham B9 4NH, United Kingdom. E-mail: S.J.HARRAD@bham.ac.uk

How to cite this article: Harrad S, Tsang DCW, Boontanon SK, Luo XJ, Abafe OA, Bagheri H, Eljarrat E, Wang T, Martincigh B, AlMamun H, Mao HJ, Mahmood A, Poma G, Rauert C, Melymuk L. Welcome to the Journal of Environmental Exposure Assessment. J Environ Expo Assess 2021;1:1. https://dx.doi.org/10.20517/jeea.2021.01

Received: 26 Jul 2021 Accepted: 26 Jul 2021 Available online: 27 Jul 2021

Academic Editor: Stuart Harrad Copy Editor: Yue-Yue Zhang Production Editor: Yue-Yue Zhang 
Welcome to the Journal of Environmental Exposure Assessment (JEEA). Evaluating the risk of chemical contaminants requires knowledge of BOTH exposure and hazard. To illustrate, just because exposure to a chemical above a certain level is known to elicit an adverse health effect, it does necessarily represent a problem, if exposure does not occur at or above that level. Thus, research that quantifies the level of exposure is an essential component of chemicals risk assessment. Moreover, where overall human exposure may be at a level approaching or above that considered to be potentially harmful studies that highlight the relative contribution of different exposure pathways potentially assist the development of strategies to reduce exposure - e.g., by recommending at-risk individuals limit consumption of particular foodstuffs as with fish advisories in the United States.

While there exist journals that address the toxicological implications and endpoints of chemical contaminants in humans (i.e., the hazard); we believe there is a pressing need for a journal that publishes the findings of research into the timing, pathways, and magnitude of human exposure to chemical contaminants. As an Editorial Board, we are delighted to introduce a new outlet for high quality peer reviewed papers reporting research into both external and internal exposure to organic and inorganic contaminants. We welcome reports of studies utilising experimental (e.g., environmental monitoring/biomonitoring) and/or modelling approaches. Papers that couple assessment of both exposure and hazard (e.g., by comparison to existing health-based limit values) to assess the risk to human health are encouraged. However, for many emerging contaminants, understanding of the hazard that they present is incomplete. In such instances, research that establishes that human exposure is occurring, at what magnitude, and via which pathways, is invaluable and will find a warm welcome at JEEA.

JEEA adopts the open access model of publication, consistent with the demands of research funders and scientists around the world. As an Editorial Board, we emphasize in the strongest possible terms that this will in no way compromise the integrity of the peer-review process. Rigorous peer-review is a cornerstone of excellent research and we will work to ensure that the highest standards are maintained in handling your paper. Moreover, as scientists who publish regularly ourselves, we appreciate fully the importance of rapid processing times for our articles, and rapid turn-round times for submitted papers is another aim of JEEA.

In conclusion, we hope that you as: authors, readers, and peer-reviewers share our enthusiasm for JEEA and its provision of a high quality outlet for new research findings in the area of human exposure to chemical contaminants. We look forward to reading about your research in future issues. The Inaugural Issue of our journal will be officially launched in the first quarter of 2022. The accepted manuscript will be online released in advance in the following months.

\section{DECLARATIONS}

\section{Authors' contributions}

Drafted the manuscript: Harrad S

Revised the manuscript critically: Tsang DCW, Boontanon SK, Luo XJ, Abafe OA, Bagheri H, Eljarrat E, Wang T, Martincigh B, Al-Mamun H, Mao HJ, Mahmood A, Poma G, Rauert C, Melymuk L

\section{Availability of data and materials}

Not applicable.

\section{Financial support and sponsorship}

None. 


\section{Conflicts of interest}

All authors declared that there are no conflicts of interest.

\section{Ethical approval and consent to participate}

Not applicable.

\section{Consent for publication}

Not applicable.

\section{Copyright}

(C) The Author(s) 2021. 